for nosocomial infections in neutropenic patients are not standardized, comparison of rates of sitespecific nosocomial infection in cancer centers is difficult. Standardized definitions also would facilitate the validation of outcome criteria in multiinstitutional antimicrobial clinical trials. Further analysis of risk factors and efficacy of infection control measures as well as interinstitutional comparisons of infection rates based on standardized criteria in populations with unique risk factors should be pursued.

\section{REFERENCES}

1. Robinson G, Tegtmeier B, Zaia J. Nosocomial infection rates in a cancer treatment center. Infect Control 1984;5:289-294.

2. Garner J, Jarvis W, Emori TG, Horan T, Hughes J. CDC definitions for nosocomial infection. Am $J$ Infect Control $1988 ; 16: 128-140$.

3. Sickles E, Greene W, Wiernik PH. Clinical presentation of infection in granulocytopenic patients. Arch Intern Med 1975;135:715-719.

4. National Nosocomial Infections Surveillance System, Centers for Disease Control. Nosocomial infection rates for interhospital comparison: limitations and possible solutions. Infect Control Hosp Epidemiol 1991;12:609-621.

\title{
AHA to Sponsor National Teleconference on TB
}

\section{by Gina Pugliese, RN, MS Medical News Editor}

The American Hospital Association will air a teleconference on June 24, 1993, entitled "Environmental Control for TB in Hospitals," focusing on engineering and environmental controls for preven- tion and control of tuberculosis. Faculty will include Dr. William Jarvis of the CDC, Andrew Streifel from the University of Minnesota Hospitals and Clinics, Dr. Edward Nardell of the Massachusetts Department of Health, and Gina Pugliese, RN, MS, of the American Hospital Association. The telecon- ference will highlight environmental controls, including ventilation systems, HEPA filtration and ultraviolet germicidal irradiation, and the pros and cons of each approach. Case studies of successful programs also will be included. For further information, contact (800) 999-4242. 